\title{
Alcohol use trajectories among adults in an urban area after a disaster: evidence from a population-based cohort study
}

\author{
Magdalena Cerda', ${ }^{1,2}$ David Vlahov ${ }^{2,3}$, Melissa Tracy' \& Sandro Galea ${ }^{1,2,3}$ \\ Department of Epidemiology, University of Michigan, Ann Arbor, MI, USA,' New York Academy of Medicine, New York, NY, USA, ${ }^{2}$ Mailman School of Public Health, \\ Columbia University, New York, NY, USA ${ }^{3}$
}

\begin{abstract}
Alcohol use increased in the New York City (NYC) metropolitan area in the first months after the 11 September 2001 terrorist attacks. Aims To investigate alcohol use trajectories in the NYC metropolitan area in the 3 years after 11 September and examine the relative contributions of acute exposure to the attacks and ongoing stressors to these trajectories. Design We used a population-based cohort of adults recruited through a random-digit-dial telephone survey in 2002; participants completed three follow-up interviews over 30 months. Setting The NYC metropolitan area. Participants A total of 2752 non-institutionalized adult residents of NYC. Measurements We used growth mixture models to assess trajectories in levels of total alcohol consumption and bingeing in the past 30 days, and predictors of these trajectories. Findings We identified five trajectories of alcohol consumption levels and three bingeing trajectories. Predictors of higher levels of use over time included ongoing stressors, traumatic events and lower income. Ongoing exposure to stressors and low income also play a central role in bingeing trajectories. Conclusions While point-in-time mass traumatic events may matter in the short term, their contribution subsides over time. Accumulated stressors and traumatic events, in contrast, lead to higher levels of consumption among respondents already vulnerable to high alcohol use. Interventions to mitigate post-disaster stressors may have substantial benefit in reducing alcohol abuse in the medium- to long term.
\end{abstract}

Keywords Alcohol use, bingeing, disasters, growth mixture, stressors, trajectories, trauma.

Correspondence to: Magdalena Cerdá, Department of Epidemiology, University of Michigan, 109 Observatory St, Room 3632, Ann Arbor, MI 481092029, USA. E-mail: mcerda@umich.edu

Submitted 18 October 2007; initial review completed 3 January 2008; final version accepted 25 March 2008

\section{BACKGROUND}

Patterns of alcohol use vary over the life course [1-6]. These include people who are stable non-users or who have stable low-use alcohol histories, stable high-use alcohol drinkers, people who 'mature out' of heavy drinking over time and those who drink more and more alcohol over time or report late onset of heavy alcohol use [7]. It is likely that different trajectories of alcohol use over the life course suggest distinct etiological profiles of problem drinking. Understanding what distinguishes, for example, stable high-level consumers from those who start out with high levels of alcohol use but decrease over time is important for developing more informed etiological models and developing effective interventions aimed at preventing heavy alcohol consumption.
Preliminary research indicates that stressful and traumatic life events over the life course can play a critical role in generating different pathways of risk behaviors, including alcohol use [8-12]. Sartor et al. [9] found that, among offspring of male twins from the Vietnam Era Twin Registry, parental divorce during childhood was associated with early alcohol initiation. Windle et al. [11] investigated trajectories of heavy alcohol use from adolescence to adulthood and found that stressful and traumatic life events, such as death of a parent or failing one or more subjects, were associated with a higher likelihood of belonging to a heavy use group among males. This study examined the influence of stressful events at only one point in time instead of comparing the relative impact of acute versus accumulated stressors. Although these studies indicate that life events may play 
an important role in shaping alcohol use trajectories, we know little about how the accumulation of stressful and traumatic events over the life course influence alcohol use trajectories.

Disaster events offer an important opportunity to consider the influence of acute life events on alcohol use trajectories at a population level. Such events affect the whole population in the area of influence. Moreover, as they affect people in a random manner, disaster events are free from selection bias: alcohol use patterns are not likely to make people more vulnerable to have direct exposure to a disaster.

We are not aware of any studies that have looked at alcohol use trajectories in the post-disaster context. The extant literature measuring patterns of alcohol consumption at single time-points after natural disasters [13-16] offers conflicting results, while studies investigating the impact of terrorist events [17-19] do not compare alcohol levels in those exposed to attacks to comparable respondents who had not experienced an attack. Some studies have found a short-term impact of natural disaster exposures on alcohol use or related substance use. Reijneveld et al. [16], for example, found that adolescents exposed to a fire in a café in Volendam, the Netherlands, that resulted in 250 wounded adolescents and killed 14, reported more excessive use of alcohol than controls. In contrast, Kohn et al. [13] did not find a higher risk of alcohol misuse among elderly people exposed to Hurricane Mitch in Honduras. A need exists to move beyond studies that examine the impact of disasters at a static point of time to research that examines the impact of acute stressful life events on different pathways of substance use over the long term, and within the broader context of ongoing life stressors that may play a role in the determination of substance use.

This study examines the trajectories of alcohol use and bingeing in the aftermath of the World Trade Center (WTC) disaster that took place in New York City on 11 September 2001. The attacks were the largest humanmade disaster in the United States since the Civil War: in New York City alone, 2726 people died and a large part of lower Manhattan suffered extensive damage from the attacks [20]. Previous research has documented an increase in alcohol use in the short term after the 11 September terrorist attacks [20-22], and a few population-based studies have found an association between exposure to the attacks and alcohol use [23,24]. However, research has been limited to the first few months after the disaster and has been cross-sectional: no prospective studies have assessed the long-term impact that exposure to the attacks had on alcohol use. More importantly, no studies have compared the impact of disasters to the influence that daily sources of stress and trauma have on alcohol use. This is a particularly impor- tant issue in the post-disaster context, when stressors and traumatic events may be particularly prevalent. Understanding the impact that the attack itself, in contrast to post-event cumulative stressors and traumatic events, has on alcohol use can help policy makers determine how to allocate resources to facilitate the post-disaster recovery process. In this study we set out to (i) document the trajectories of alcohol use after a large-scale human made disaster; and (ii) assess the relative role of exposure to a disaster and ongoing stressors in influencing the trajectories of alcohol use over several years. We examined alcohol use in two ways: (i) the trajectories of the full range of alcohol consumption from no use to regular high levels of consumption; and (ii) the particular patterns of heavy alcohol consumption, or bingeing, in the aftermath of the 11 September 2001 terrorist attacks.

\section{METHODS}

\section{Sample}

We conducted a prospective, population-based cohort study of the adult population of the New York City (NYC) metropolitan area. The cohort was assembled to assess the mental health of the NYC metropolitan area population approximately 6 months after the WTC disaster. Methods are described in detail elsewhere [25]. Respondents were sampled through simple area probability random-digit-dialing between 25 March 2002 and 25 June 2002. Adults in each household were selected randomly by choosing the adult whose birthday was closest to the interview date. The study had a survey cooperation rate of $56 \%$ and a response rate of $36 \%$. Interviews were conducted in English, Spanish, Mandarin and Cantonese by trained interviewers using back-translated questionnaires and a computer-assisted telephone interview system.

Participants were followed approximately 6 months after baseline (25 September 2002-31 January 2003) and subsequently at yearly intervals (25 September 2003-29 February 2004, 15 December 2004-30 November 2005). Hence, the study follows participants approximately 6, 12, 24 and 39 months after the occurrence of the WTC disaster.

The original sample consisted of 2752 respondents; of these, 2282 completed at least one interview and were included in this study; $46 \%$ completed all four interviews. Among those who missed interviews, 21\% missed one interview, $16 \%$ missed two and $17 \%$ missed three. There were no differences between included and excluded respondents on prevalence of bingeing and level of alcohol consumption or exposure to the WTC disaster, traumatic experiences or stressors at baseline; however, the excluded respondents were less likely to be females, 
and more likely to be Hispanic, between 25 and 34 years of age, single and to have a high school-level education than the included respondents. The included respondents were $45.3 \%$ male, $60.6 \%$ white, $5.7 \%$ Asian, $14.1 \%$ African American and 16.2\% Hispanic and 3.3\% other race/ethnicity. The mean age was 44.7 years. The analytical sample has been shown to be representative of the NYC population based on 2000 Census data [26].

\section{Measures}

Alcohol consumption was assessed in two ways at each interview: (1) total number of drinks consumed per day in the past 30 days and (2) bingeing, defined as a binary variable, denoting having consumed an average of five or more drinks per day in the past 30 days for male respondents and as consuming an average of four or more drinks for females. Total consumption in the past 30 days was calculated by multiplying the number of days on which respondents reported to have drunk alcohol in the past 30 days (i.e. 'thinking about just the past 30 days, on how many days did you drink any alcoholic beverages?') and the average number of drinks reported per day (i.e. 'on the days when you drank alcohol over the past 30 days, on average, how many drinks did you have each day?'). Alcohol consumption was first assessed in the baseline survey for the 30 days prior to the 11 September 2001 terrorist attacks, and also for the 30 days prior to the interview. In subsequent interviews, respondents were asked only about the number of drinks consumed per day for the past 30 days. All five times of measurement of alcohol use (i.e. the retrospective report of alcohol consumption on the 30 days prior to 11 September, and the reports of consumption on the 30 days prior to the baseline and three follow-up interviews) were used in the analysis.

We also measured characteristics that, in previous work, have been shown to be associated with alcohol consumption [27-34]. Demographic variables included age, gender, race/ethnicity, education, low income (defined as earning less than \$30 000 per year) and marital status. Direct exposure to the attacks of 11 September 2001 was operationalized as having: been in the WTC complex during the attacks, been injured during the attacks, lost possessions or property due to the attacks, had a friend or relative killed, lost a job as a result of the attacks, or been involved in the rescue effort. We also measured peri-event emotional reactions after the WTC attacks with a modified version of the Diagnostic Interview Schedule subscale for panic [35]. The presence of four or more symptoms listed in the Diagnostic and Statistical Manual (DSM-IV) within the first few hours after the WTC attacks served to classify respondents as having had a peri-event emotional reaction. Respondents were also asked about the occurrence of any of 12 traumatic events (natural disaster; serious accident at work, in a car, or somewhere else; assault with a weapon; assault without a weapon; unwanted sexual contact; serious injury or illness; other situation involving serious injury or physical damage; situation causing fear of death or serious injury; seeing someone seriously injured or violently killed; death of a spouse or mate; death of a close family member other than a spouse; any other extraordinarily stressful situation or event) in their life-time at baseline; at each subsequent interview, respondents were questioned about traumatic events that had occurred since the previous interview. We also asked about stressors that may be experienced in daily life and that are not considered traumatic events. These included divorce or separation, marriage, family problems, problems at work and unemployment. During the baseline interview, respondents reported stressors that had occurred in their life-time; at each subsequent interview, stressors occurring since the previous interview were assessed. The life stressor scale was developed for the nationally representative National Women's Study and National Survey of Adolescents [36-38] to represent the universe of life course major stressors, and has been shown to have high content validity and to be highly predictive of adverse mental health and wellbeing throughout the life course [26,39]. Each trauma or stressor was reported dichotomously by respondents, and sums of these events (sum of traumas, sum of stressors) at baseline or during the previous follow-up period were included in the analysis. Given that alcohol use reports for the first two time-periods were measured at the same baseline interview, we had to assume that the time-varying covariates did not vary between these two time-points.

\section{Analysis}

We used sampling weights to adjust for potential selection bias related to the number of telephones in respondent households, people in the household and over-sampling of zones closest to the WTC. We conducted analyses using semi-parametric group-based modeling, which we used to identify the number of alcohol bingeing and consumption level trajectories and to determine the impact that socio-demographic characteristics and exposure to the WTC attacks had on trajectory group membership.

Group-based models serve to identify clusters of individuals that follow similar paths of behavior over time [40]. Rather than capturing variability in developmental trajectories through a random coefficient as do traditional growth curve models, group-based models assume that the sample is composed of a mixture of underlying trajectory groups, each defined by an average growth curve [7]. We used a binary logit distribution to model 
Table 1 Parameters for five-group trajectory model for level of alcohol consumption.

\begin{tabular}{|c|c|c|c|c|}
\hline Group & $\begin{array}{l}\text { Average group posterior } \\
\text { probability }\end{array}$ & Parameter & Estimate & Standard error \\
\hline Stable non-drinkers & 0.91 & Intercept & $-18.48^{* * *}$ & 1.32 \\
\hline \multirow[t]{2}{*}{ Low users } & 0.89 & Intercept & $2.76^{*}$ & 1.09 \\
\hline & & Linear & $0.15^{* * *}$ & 0.03 \\
\hline \multirow[t]{2}{*}{ Increasing users } & 0.82 & Intercept & 10.53 & 6.63 \\
\hline & & Linear & $0.88^{*}$ & 0.41 \\
\hline \multirow[t]{2}{*}{ Decreasing users } & 0.83 & Intercept & $34.92^{* * *}$ & 8.67 \\
\hline & & Linear & -0.36 & 0.28 \\
\hline \multirow[t]{3}{*}{ High stable users } & 0.95 & Intercept & $56.28^{* * *}$ & 3.28 \\
\hline & & Quadratic & 0.33 & 0.63 \\
\hline & & Cubic & -0.006 & 0.01 \\
\hline \multicolumn{5}{|l|}{ Group membership } \\
\hline Stable non-drinkers & & $(\%)$ & $45.29^{* * *}$ & 2.24 \\
\hline Low users & & $(\%)$ & $39.41^{* * *}$ & 1.94 \\
\hline Increasing users & & $(\%)$ & 5.01 & 2.96 \\
\hline Decreasing users & & $(\%)$ & $6.24^{*}$ & 2.75 \\
\hline High stable users & & $(\%)$ & $4.04^{* * *}$ & 0.81 \\
\hline
\end{tabular}

${ }^{*} P<0.05 ; * * * P<0.001$.

bingeing and a censored normal distribution to model level of total alcohol consumption. We fitted separate models with two to six trajectory groups for bingeing and level of consumption, and used the Bayesian information criterion (BIC) to select the best-fitting model. Once we had selected the optimal number of groups for each outcome, we determined the optimal number of parameters used to define the shape of each trajectory group (i.e. linear, quadratic, cubic) by their significance at the $P<0.05$ significance level. Covariates were finally added to the best-fitting group trajectory models: time-stable baseline covariates were incorporated assuming that they affected the probability of belonging to a particular group in contrast to a reference group, while time-varying covariates measured at each assessment point were assumed to affect the shape of each specific trajectory at each timepoint [41]. In other words, a unit change in a timevarying covariate is associated with a change in the outcome at each measurement point, conditional on each specific outcome trajectory. Although we started with the same set of covariates for bingeing and level of consumption, the final models presented here include only those covariates that were associated with at least one trajectory group in the respective models. The only exception is direct exposure to the WTC attacks and perievent emotional reactions related to the attacks, which we kept regardless, given that they were two of the main predictors of interest. Although the associations of trajectory groups with baseline and time-varying covariates are drawn from the same model, separate tables are presented for each type of predictor: baseline covariates predict membership in trajectory groups relative to a reference group, while time-varying covariates have an estimated association with the outcome for each separate trajectory. The coefficients presented in the tables for time-varying covariates are the trajectory-specific weighted average of the association of the covariate with the outcome for individuals experiencing the exposure at different points in time.

Dual-trajectory models were finally used to describe the relationship between class membership in the consumption classes and class membership in the bingeing classes. These models estimate jointly the trajectories for two different outcomes, and estimate probabilities linking membership in trajectory groups across outcomes.

\section{RESULTS}

\section{Identification of alcohol trajectories}

Level of alcohol consumption trajectories

The five-group trajectory model provided the best fit for the alcohol consumption level data. Average posterior group membership probabilities for the five-group model ranged between 0.82 and 0.95 (Table 1). The empirical growth curves for the five identified trajectory groups for level of alcohol consumption are shown in Fig. 1. The largest group (45.3\% of sample) consisted of respondents who reported less than one drink in the past 30 days throughout the study period (hereby referred to as the 'stable non-drinker' group), while the second-largest group (39.4\% of sample) exhibited consistently low levels of drinking (hence labeled the 'low-user' group). One of the groups (5.01\% of sample) started with a low level of 
$\%$ of sample

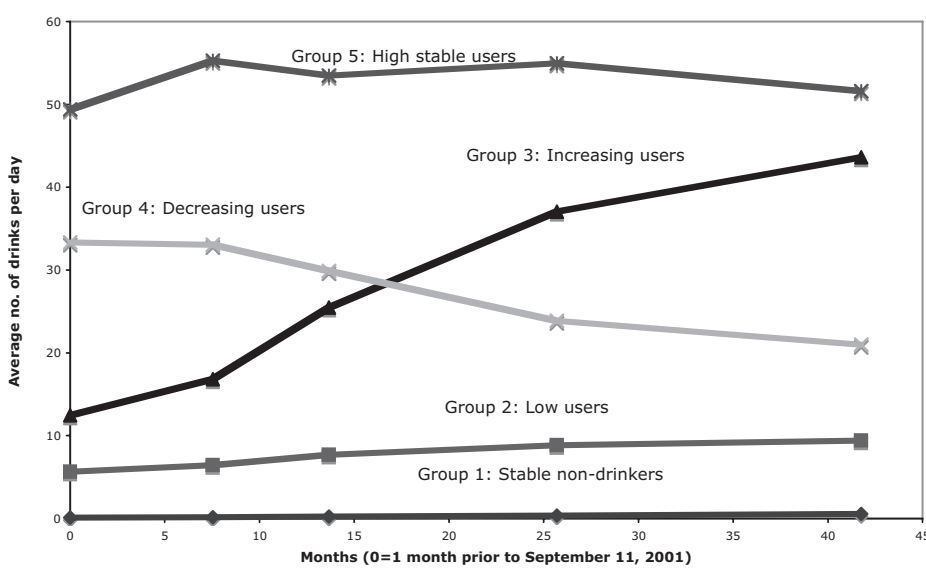

$4.04 \%$

$5.03 \%$

$6.2 \%$

$39.4 \%$

$45.3 \%$
Figure I Trajectories of alcohol consumption levels after I I September 200I, New York City

Table 2 Parameters for three-group trajectory model for alcohol bingeing prevalence.

\begin{tabular}{|c|c|c|c|c|}
\hline Group & $\begin{array}{l}\text { Average group posterior } \\
\text { probability }\end{array}$ & Parameter & Estimate & Standard error \\
\hline Stable non-bingers & 0.97 & Intercept & $-4.39^{* * *}$ & 0.27 \\
\hline \multirow[t]{3}{*}{ Later bingeing onset } & 0.91 & Intercept & $-2.66^{* * *}$ & 0.57 \\
\hline & & Linear & $0.19^{*}$ & 0.09 \\
\hline & & Quadratic & -0.002 & 0.00 \\
\hline \multirow[t]{4}{*}{ Bingeing desisters } & 0.98 & Intercept & $12.29^{* * *}$ & 2.88 \\
\hline & & Linear & $-1.65^{* * *}$ & 0.41 \\
\hline & & Quadratic & $0.06^{* * *}$ & 0.02 \\
\hline & & Cubic & $-0.001^{* * *}$ & 0.00 \\
\hline \multicolumn{5}{|l|}{ Group membership } \\
\hline Stable non-bingers & & $(\%)$ & $89.96^{* * *}$ & 2.19 \\
\hline Later bingeing onset & & $(\%)$ & $5.38^{* *}$ & 2.07 \\
\hline Bingeing desisters & & $(\%)$ & $4.65^{* * *}$ & 0.69 \\
\hline
\end{tabular}

${ }^{*} P<0.05 ;{ }^{* *} P<0.01 ;{ }^{* * *} P<0.001$.

drinking and then increased markedly over the years (hereby known as the 'increasing user' group), while another group ( $6.2 \%$ of sample) showed a slight decrease from a moderate level of drinking (approximately one drink per day in the past 30 days) to a low-moderate level of consumption (labeled the 'decreasing user' group). Finally, the smallest group ( $4.0 \%$ of the sample) showed a consistently high level of alcohol consumption across time (labeled herein the 'high stable users' group).

\section{Prevalence of bingeing trajectories}

The three-group trajectory model was selected as the best model to fit the alcohol bingeing data. Although the four-group trajectory model had a lower BIC, three of the groups included between $2.7-6.9 \%$ of the sample and the posterior group membership probability for one of the groups was only 0.5 . Hence, we selected the three-group model instead. Average posterior group membership probabilities for the three-group model ranged between 0.91 and 0.98 (Table 2). The observed growth curves for the three-trajectory group model are shown in Fig. 2. Among the largest group $189.9 \%$ of sample), approximately $1.0 \%$ of the respondents reported consuming five+/four+ drinks at each study wave (labeled the 'stable non-bingers'). Two small groups reported changes in the prevalence of bingeing over time: in one group $(5.4 \%$ of sample; labeled the 'later bingeing onset' group) $8.3 \%$ of the respondents reported, at baseline, having consumed an average of five+/four+ drinks per day 2 weeks before 11 September 2001 , but $58.3 \%$ of the sample reported such bingeing by the last study wave; in the other group $(4.7 \%$ of sample; labeled the 'bingeing desisters' ), $100 \%$ of the respondents reported heavy drinking at the beginning of the study, but by the end of the study only $9.5 \%$ of the members binged on a daily basis. 
Figure 2 Trajectories of bingeing prevalence after II September 200 I, New York City

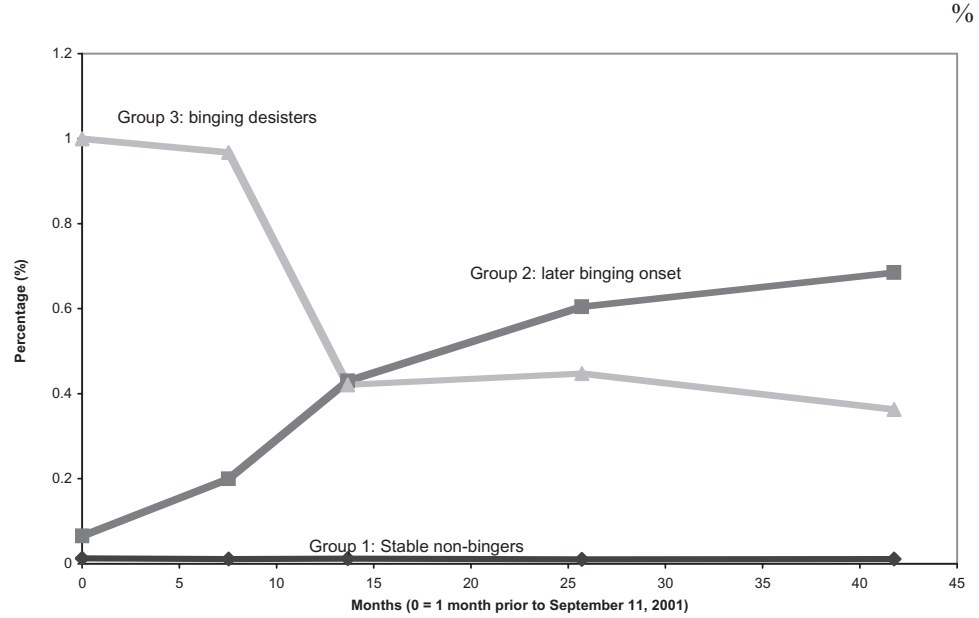

$5.38 \%$

$4.65 \%$

$89.9 \%$

Table 3 Time-varying covariates associated with course of alcohol level of use trajectoriest.

Alcohol level of use trajectories

\begin{tabular}{lccccc}
\hline & Stable non-drinkers & Low users & Increasing users & Decreasing users & Stable high users \\
\cline { 2 - 5 } & Beta & Beta & Beta & Beta & Beta \\
\hline Low income $(<\$ 3000)$ & $-6.17^{* *}$ & $-5.76^{* * *}$ & 0.01 & $-9.19^{*}$ & 0.66 \\
Number of daily stressors & 1.34 & 0.80 & $8.46^{* *}$ & 1.35 & $-5.90 \sim$ \\
$\begin{array}{l}\text { Number of traumatic } \\
\quad \text { experiences }\end{array}$ & 0.74 & 0.46 & -1.21 & $-4.4 \sim$ & $7.69^{*}$
\end{tabular}

${ }^{*} P<0.05 ;{ }^{* *} P<0.01 ;{ }^{* * *} P<0.001 ; \sim P<0.10$. $\dagger$ Controlling for age, race/ethnicity, sex, marital status, education, exposure to the World Trade Center disaster and emotional reactions to the event.

\section{Socio-demographic characteristics of alcohol use trajectory groups}

\section{Level of alcohol consumption}

The time-varying covariates associated with the course of the trajectory groups for level of alcohol consumption are presented in Table 3. Having a low income was associated with a lower level of alcohol consumption for the stable non-drinkers, the low users and the decreasing users. Reporting a higher number of stressors in daily life throughout the study resulted in a higher level of consumption for the increasing users, while reporting a higher number of traumatic events was associated with a higher level of consumption for the high stable users.

Table 4 presents the association of baseline covariates with the likelihood of membership in each trajectory group, relative to the stable non-drinker group. In a model controlling only for stressors and traumatic events (model not shown), exposure to the WTC was associated with a higher likelihood of membership in the increasing user group than in the stable non-drinker group, while having experienced an emotional reaction to the event was associated with a lower likelihood of belonging to the high stable drinker group than the stable nondrinker group. Once we controlled for baseline sociodemographic characteristics, however (Table 4), these associations disappeared.

\section{Prevalence of bingeing trajectories}

The time-varying covariates associated with the course of the trajectory groups for prevalence of bingeing are presented in Table 5. Within the group which had a consistently low number of bingers, having a low income throughout the course of the study was associated with a lower prevalence of bingeing, while exposure to a higher number of stressors was associated with an increased prevalence of bingeing. No other time-varying covariates were significant, and are thus not included in the final model.

At a bivariate level, having had an emotional reaction to the WTC attacks was associated with a lower likelihood of membership in the bingeing desister group than in the stable non-binger group (model not shown). Once we controlled for the baseline socio-demographic characteristics presented in Table 6, however, neither exposure to 
Table 4 Baseline covariates associated with alcohol level of use trajectory membership $\dagger$.

\begin{tabular}{|c|c|c|c|c|}
\hline & Low users & Increasing users & Decreasing users & Stable high users \\
\hline & Beta & Beta & Beta & Beta \\
\hline \multicolumn{5}{|l|}{ Age (18-34 reference) } \\
\hline $35-54$ & 0.10 & 0.04 & -0.21 & -0.35 \\
\hline $55+$ & $-0.78^{* *}$ & -0.40 & $-0.97^{* * * *}$ & $-0.83^{* * * *}$ \\
\hline Female & $-0.76^{* * *}$ & $-1.48^{* * *}$ & $-0.94^{*}$ & $-2.49^{* * *}$ \\
\hline \multicolumn{5}{|l|}{ Race/ethnicity (white reference) } \\
\hline Asian & $-1.25^{* *}$ & $-15.42^{* * *}$ & $-2.49^{* *}$ & $-2.23^{*}$ \\
\hline Black & $-1.03^{* * *}$ & $-1.63^{*}$ & $-2.29^{*}$ & $-2.80^{* *}$ \\
\hline Hispanic & $-0.92^{* *}$ & $-2.02^{* * *}$ & $-1.06^{* * * *}$ & $-1.81^{* *}$ \\
\hline Other & -0.65 & $-1.76^{*}$ & $-1.68^{* * * *}$ & $-3.81^{* * *}$ \\
\hline \multicolumn{5}{|c|}{ Marital status (married reference) } \\
\hline $\begin{array}{l}\text { Divorced/ separated/ } \\
\text { widowed }\end{array}$ & 0.05 & -0.12 & 0.03 & 0.51 \\
\hline $\begin{array}{l}\text { Single/ unmarried } \\
\text { cohabiting }\end{array}$ & $0.50^{*}$ & $0.83^{* * * *}$ & $1.85^{* * *}$ & $1.68^{* * *}$ \\
\hline \multicolumn{5}{|l|}{ Education (college reference) } \\
\hline $\begin{array}{l}\text { High school/general } \\
\text { educational development }\end{array}$ & $-0.49^{*}$ & -0.29 & -0.85 & 0.35 \\
\hline Less than high school & -0.62 & $-3.95^{* *}$ & 0.21 & -1.11 \\
\hline \multicolumn{5}{|l|}{ Trauma and stress } \\
\hline $\begin{array}{l}\text { Directly affected by } 11 \\
\text { September }\end{array}$ & 0.11 & 0.56 & -0.33 & -0.47 \\
\hline $\begin{array}{l}\text { Emotional reactions to } 11 \\
\text { September }\end{array}$ & -0.03 & 0.26 & -0.88 & -1.50 \\
\hline
\end{tabular}

${ }^{*} P<0.05 ; * * P<0.01 ;{ }^{* * *} P<0.001 ;{ }^{* * * *} P<0.10$. †Controlling for low income, number of traumatic experiences and daily stressors at each time-point.

Table 5 Time-varying covariates associated with course of alcohol bingeing trajectoriest.

\begin{tabular}{|c|c|c|c|}
\hline \multicolumn{4}{|l|}{ Alcohol bingeing trajectories } \\
\hline & Stable non-bingers & Later bingeing onset & Bingeing desisters \\
\hline & Beta & Beta & Beta \\
\hline Low income $(<\$ 30000)$ & $-2.28^{*}$ & 0.13 & -0.21 \\
\hline Number of stressors & $1.73^{* * *}$ & -0.25 & 0.24 \\
\hline
\end{tabular}

${ }^{*} P<0.05$; ${ }^{* * *} P<0.001$. $\dagger$ Controlling for age, race/ethnicity, sex, marital status, education, exposure to the WTC disaster and emotional reactions to the event.

the WTC attacks nor emotional reactions to the event were associated with membership in any of the bingeing trajectory groups.

\section{Dual trajectories}

The dual-trajectory model included three consumption classes and three bingeing classes. Although the consumption single-trajectory model had included five classes, it became necessary to reduce it to three classes in order for the dual-trajectory model to converge.
Figures 3-5 present three alternative representations of the linkages between consumption levels and bingeing. One is the probability of membership in the bingeing classes, conditional upon membership in the consumption classes (Fig. 3). Figure 4 presents the reverse set of probabilities: probability of membership in the consumption classes, conditional upon membership in the bingeing classes. The third form of presentation, Fig. 5, is the joint probability of membership in the consumption and bingeing classes. The three figures show a strong linkage between the trajectories for the two manifestations of 
Table 6 Baseline covariates associated with alcohol bingeing trajectory membership $\dagger$.

Alcohol bingeing trajectories (relative to stable non-binger group)

\begin{tabular}{|c|c|c|}
\hline & Later bingeing onset & Bingeing desisters \\
\hline & Beta & Beta \\
\hline \multicolumn{3}{|l|}{ Age (18-34 reference) } \\
\hline $35-54$ & $8.03^{*}$ & 6.16 \\
\hline $55+$ & $-28.19^{* * *}$ & -7.49 \\
\hline Female & $-2.49^{* *}$ & $-2.49^{* *}$ \\
\hline \multicolumn{3}{|l|}{ Race/ethnicity (white reference) } \\
\hline Asian & $3.02^{* *}$ & 0.25 \\
\hline Black & $3.44^{*}$ & 0.84 \\
\hline Hispanic & $1.93^{* * * *}$ & 0.77 \\
\hline Other & -3.80 & -2.86 \\
\hline \multicolumn{3}{|l|}{ Marital status (married reference) } \\
\hline Divorced/separated/widowed & 1.22 & $1.88^{* * * *}$ \\
\hline Single/unmarried cohabiting & -0.16 & $1.66^{*}$ \\
\hline \multicolumn{3}{|l|}{ Education (college reference) } \\
\hline High school/general educational development & -6.34 & -4.31 \\
\hline Less than high school & $-9.53^{*}$ & -5.80 \\
\hline \multicolumn{3}{|l|}{ Experience of 11 September } \\
\hline Directly affected by 11 September & -0.18 & -0.14 \\
\hline Emotional reactions to 11 September & - & -5.79 \\
\hline
\end{tabular}

${ }^{*} P<0.05 ;{ }^{* *} P<0.01 ;{ }^{* * *} P<0.001 ;{ }^{* * * *} P<0.10$. †Controlling for low income and daily stressors at each time-point.

Figure 3 Probability of bingeing group conditional on alcohol consumptionlevel group

Figure 4 Probability of drinking consumption level group conditional on alcohol consumption bingeing group

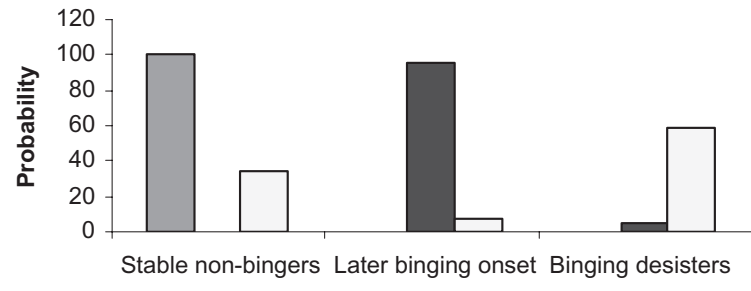

$\square$ Stable non-drinkers

$\square$ Low users

$\square$ Stable high users

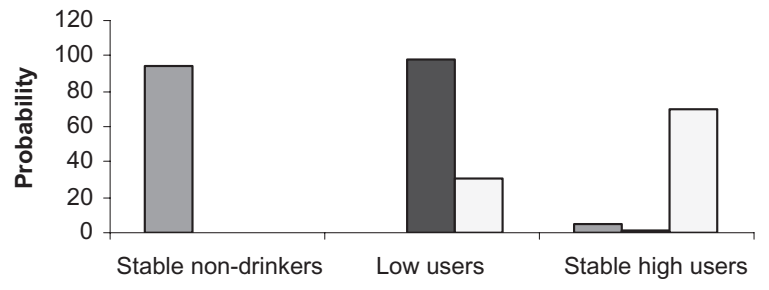

$\square$ Stable non-bingers

$\square$ Later binging onset

$\square$ Binging desisters

alcohol use. Figure 3 indicates that the stable nondrinkers were only members of the stable non-binger class, while the low users were most likely to belong to the later bingeing onset class and the stable high users were most likely to belong to the bingeing disasters group. The high degree of overlap in classes was also reflected in Fig. 5, where the two most prevalent joint probabilities were for the overlap of stable non-bingers and stable nondrinkers, as well as low users and those experiencing later bingeing onset.

\section{DISCUSSION}

This is one of the first studies to examine the joint influence of ongoing stressors and traumatic event experiences during the life course on different alcohol use trajectories. Using data from a population-based cohort of NYC and applying semi-parametric group-based modeling, we confirmed that a great level of heterogeneity exists in drinking pathways among adults [2]. The five trajectory groups we detected for consumption levels are 


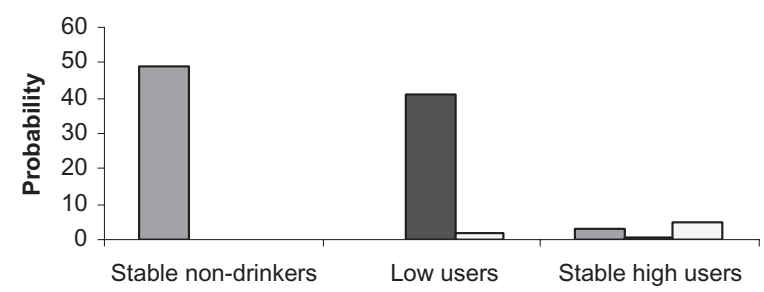

consistent with those found by previous research conducted with adolescents and young adults: longitudinal studies using mixture models have identified a range from four to six trajectory groups, including a group of regular users, non-users, and a range of groups that show increasing or decreasing levels of consumption throughout the study period $[2,4,42-44]$. We also identified three bingeing groups, which are consistent with previous studies of adults: studies with participants in middle and older adulthood [43,45] indicate that heavy drinking subsided in later adulthood, and heavy drinking trajectories were restricted to four groups, including stable, declining, curvilinear and abstainers. Our findings indicate that while the level of heterogeneity in severe levels of drinking may decrease after young adulthood, the general patterns of variation in alcohol consumption levels persist in adulthood, after developmental changes have been established. The dual-trajectory analysis also provides a more comprehensive understanding of the different forms of alcohol use as it indicates, for example, that respondents who showed a low degree of use over time may have experienced later onset of bingeing, while those who had a consistently high degree of alcohol consumption may have desisted from bingeing over time.

One of the main motivations for this study was to investigate the long-term impact that exposure to an acute disaster had on different types of alcohol use trajectories, relative to ongoing exposure to accumulated stressors and traumatic events in the post-disaster setting. In a previous comparison of two cross-sectional samples in two time-periods, we had found that exposure to the attacks was not associated with an increase in alcohol use 6 months after 11 September, but that a peri-event emotional event did predict an increased rate of use [21]. In this new prospective long-term study, we found that neither exposure to the 11 September 2001 terrorist attacks nor experience of a peri-event emotional reaction differentiated between different trajectories of alcohol consumption levels or bingeing over the 4 years following this event. This study expands on previous work in several ways. First, it presents a stronger design, as we followed the same respondents over time rather than comparing levels of alcohol use in two different cross-sectional samples. Secondly, we considered the specific impact of the attacks on the trajectories followed by distinct types of

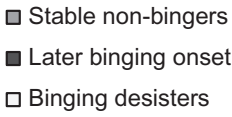

Figure 5 Joint probability of alcoho consumption-level group and bingeing group alcohol users and bingers over several years after the attacks. Thirdly, we followed the respondents over the long term, and found that the impact of an acute disaster on alcohol use subsides over time.

Another key contribution of this study involves finding that while the acute experience of the attacks did not predict long-term alcohol consumption patterns, ongoing post-disaster exposure to traumatic events and stressors was a consistent predictor of alcohol use and bingeing trajectories. We are not aware of other studies that have examined the impact that post-disaster cumulative stressors and traumatic events have on different types of alcohol consumers over time. Concurrent exposure to trauma seems to be associated with increased consumption among adult constant consumers of high levels of alcohol: more ongoing experiences of traumatic events were associated with an increased mean number of drinks consumed in the past 30 days among the high stable alcohol users. These findings build upon previous studies of adolescent and young adult substance use trajectories, which found that baseline traumatic events such as the death of a loved one contributed to a higher likelihood of belonging to a heavy or very heavy drinking trajectory group rather than a non-heavy drinking stable group [11] and discriminated smoker groups from the abstainers [46]. Alcohol has been proposed to act as a mechanism to cope with stress or to medicate symptoms of post-traumatic stress disorder (PTSD) [11,20,23,4750].

We also found that ongoing exposure to stressors, such as financial problems or divorce, played a role in predicting trajectories of adult alcohol use and bingeing $[20,31,51,52]$. Ongoing stressors were associated with a higher level of consumption among the increasing users group as well as with an increased number of bingers in the stable non-binger group. The contribution of ongoing stressful life events to the risk of higher alcohol consumption among people who already showed a tendency to increase their level of alcohol use over time, as well as to the risk of shifting to heavy levels of use, seem particularly important to consider in the post-disaster setting, given that disasters themselves have been shown to incite fear and economic instability [25]. Hence, the stressful circumstances that result from the attacks may have an influence on long-term population risk of alcohol use, 
distinct from the immediate impact of the traumatic event itself. Ongoing stressors have been found to play a similar role on the risk of PTSD after the WTC disaster [26]. This finding suggests that, in the aftermath of disasters, interventions that aim to mitigate the stressors that may be endemic to a post-disaster situation may have substantial population-level benefit in the medium- to long term.

Several caveats should be noted related to these findings. First, respondents' recall of alcohol use may have been less accurate for the month preceding the 11 September attacks than it was when asked about the month immediately preceding the survey. Baseline estimates of alcohol use are comparable to national estimates, however, providing some basis for confidence in selfreport measures [26]. As we used telephones to conduct our interviews, we restricted the survey to households which had telephones. We did find, however, that sociodemographic characteristics of respondents were comparable to those of the 2000 Census for the New York metropolitan area. Thirdly, as with all longitudinal studies, we had a degree of loss to follow-up, which may have resulted in a biased sample. Applications of censoring weights in another study using the same data [26] did not alter the nature of results, giving us confidence in our findings. Finally, although we did conduct a longer follow-up post-disaster than any other study of which we are aware, we may have failed to detect patterns of use that we could have detected had the follow-up continued.

In conclusion, we showed that in a longitudinal population-based sample, ongoing exposure to traumatic events and stressors plays an important role in alcohol use and bingeing trajectories, while the impact of a single mass traumatic event subsides over time. By applying multiple-trajectory approaches, we also contributed to a more specific understanding of the contributors to the heterogeneous pathways of alcohol use among adults [53]. This study indicates that in order to reduce the risk of increased alcohol abuse in a post-disaster context, public policy investment should focus not only upon managing the immediate mental health consequences of exposure to the event, but also on alleviating sources of stressors that may ensue following a mass disaster, such as loss of employment, property or the breakdown of family structures. Further, it suggests that in order to make a lasting population-level impact to prevent individuals from engaging in higher levels of consumption, sustained attention should be invested in increasing availability of social and mental health treatment services for those sectors of the population that, because of their existing social and economic vulnerability, are disproportionately more likely to experience stressors and traumatic events.

\section{Acknowledgements}

This research was supported by grants MH 66081, MH 66391, DA 13146-S2 and DA017642, DA022720 from the National Institutes of Health, Bethesda, MD, and by the Robert Wood Johnson Foundation Health and Society Scholars Program.

\section{References}

1. Duncan T. E., Duncan S. C., Alpert A., Hops H., Stoolmiller M., Muthen B. Latent variable modeling of longitudinal and multilevel substance use data. Multivariate Behav Res 1997; 32: 275-318.

2. Muthen B., Muthen L. K. Integrating person-centered and variable-centered analyses: growth mixture modeling with latent trajectory classes. Alcohol Clin Exp Res 2000; 24: 882-91.

3. Greenbaum P. E., Del Boca F. K., Darkes J., Wang C. P., Goldman M. S. Variation in the drinking trajectories of freshmen college students. J Consult Clin Psychol 2005; 73: 229-38.

4. Jackson K. M., Sher K. J. Similarities and differences of longitudinal phenotypes across alternate indices of alcohol involvement: a methodologic comparison of trajectory approaches. Psychol Addict Behav 2005; 19: 339-51.

5. Jackson K. M., Sher K. J., Schulenberg J. E. Conjoint developmental trajectories of young adult alcohol and tobacco use. J Abnorm Psychol 2005; 114: 612-26.

6. Clark D. B., Jones B. L., Wood D. S., Cornelius J. R. Substance use disorder trajectory classes: diachronic integration of onset age, severity, and course. Addict Behav 2006; 31: 9951009.

7. Wiesner M., Weichold K., Silbereisen R. K. Trajectories of alcohol use among adolescent boys and girls: identification, validation, and sociodemographic characteristics. Psychol Addict Behav 2007; 21: 62-75.

8. Duncan G. J., Wilkerson B., England P. Cleaning up their act: the effects of marriage and cohabitation on licit and illicit drug use. Demography 2006; 43: 691-710.

9. Sartor C. E., Lynskey M. T., Heath A. C., Jacob T., True W. The role of childhood risk factors in initiation of alcohol use and progression to alcohol dependence. Addiction 2007; 102: 216-25.

10. Karlamangla A., Zhou K. F., Reuben D., Greendale G., Moore A. Longitudinal trajectories of heavy drinking in adults in the United States of America. Addiction 2006; 101: 91-9.

11. Windle M., Mun E. Y., Windle R. C. Adolescent-to-young adulthood heavy drinking trajectories and their prospective predictors. J Stud Alcohol 2005; 66: 313-22.

12. Windle M., Wiesner M. Trajectories of marijuana use from adolescence to young adulthood: predictors and outcomes. Dev Psychopathol 2004; 16: 1007-27.

13. Kohn R., Levav I., Garcia I. D., Machuca M. E., Tamashiro R. Prevalence, risk factors and aging vulnerability for psychopathology following a natural disaster in a developing country. Int J Geriatr Psychiatry 2005; 20: 835-41.

14. North C. S., Kawasaki A., Spitznagel E. L., Hong B. A. The course of PTSD, major depression, substance abuse, and somatization after a natural disaster. J Nerv Ment Dis 2004; 192: 823-9.

15. Parslow R. A., Jorm A. F. Tobacco use after experiencing a major natural disaster: analysis of a longitudinal study of 2063 young adults. Addiction 2006; 101: 1044-50. 
16. Reijneveld S. A., Crone M. R., Verhulst F. C., VerlooveVanhorick S. P. The effect of a severe disaster on the mental health of adolescents: a controlled study. Lancet 2003; 362: 691-6.

17. Grieger T. A., Fullerton C. S., Ursano R. J. Posttraumatic stress disorder, alcohol use, and perceived safety after the terrorist attack on the Pentagon. Psychiatr Serv 2003; 54: 1380-2.

18. Pfefferbaum B., Doughty D. E. Increased alcohol use in a treatment sample of Oklahoma City bombing victims. Psychiatry Interpers Biol Process 2001; 64: 296-303.

19. Stewart S. H., Mitchell T. L., Wright K. D., Loba P. The relations of PTSD symptoms to alcohol use and coping drinking in volunteers who responded to the Swissair Flight 111 airline disaster. J Anxiety Disord 2004; 18: 51-68.

20. Vlahov D., Galea S., Ahern J., Vlahov D. Galea S., Ahern J. et al. Consumption of cigarettes, alcohol, and marijuana among New York City residents six months after the September 11 terrorist attacks. Am J Drug Alcohol Abuse 2004; 30: 385-407.

21. Vlahov D., Galea S., Ahern J., Rudenstine S., Resnick H., Kilpatrick D. et al. Alcohol drinking problems among New York City residents after the September 11 terrorist attacks. Subst Use Misuse 2006; 41: 1295-311.

22. Vlahov D., Galea S., Ahern J., Resnick H., Kilpatrick D. Sustained increased consumption of cigarettes, alcohol, and marijuana among Manhattan residents after September 11, 2001. Am J Public Health 2004; 94: 253-4.

23. Boscarino J. A., Adams R. E., Galea S. Alcohol use in New York after the terrorist attacks: a study of the effects of psychological trauma on drinking behavior. Addict Behav 2006; 31: 606-21.

24. Wu P., Duarte C. S., Mandell D. J., Fan B., Liu X. H., Fuller C. J. et al. Exposure to the World Trade Center attack and the use of cigarettes and alcohol among New York City public high-school students. Am J Public Health 2006; 96: 804 7 .

25. Nandi A., Galea S., Tracy M., Ahern J., Resnick H., Gershon R. et al. Job loss, unemployment, work stress, job satisfaction, and the persistence of posttraumatic stress disorder one year after the September 11 attacks. J Occup Environ Med 2004; 46: 1057-64.

26. Galea S., Ahern J., Tracy M., Hubbard A., Cerdá M., Goldmann E. et al. The longitudinal determinants of posttraumatic stress in a population-based cohort study. Epidemiology 2008; 19: 47-54.

27. Bahr S. J., Marcos A. C., Maughan S. L. Family, educational and peer influences on the alcohol-use of female and maleadolescents. I Stud Alcohol 1995; 56: 457-69.

28. Braun B. L., Hannan P., Wolfson M., Jones-Webb R., Sidney S. Occupational attainment, smoking, alcohol intake, and marijuana use: ethnic-gender differences in the cardia study. Addict Behav 2000; 25: 399-414.

29. Caetano R., Clark C. L. Trends in alcohol consumption patterns among whites, blacks and Hispanics: 1984 and 1995. J Stud Alcohol 1998; 59: 659-68.

30. Caetano R., Clark L. Trends in alcohol-related problems among whites, blacks, and Hispanics: 1984-1995. Alcohol Clin Exp Res 1998; 22: 534-8.

31. Crum R. M., Muntaner C., Eaton W. W., Anthony J. C. Occupational stress and the risk of alcohol abuse and dependence. Alcohol Clin Exp Res 1995; 19: 647-55.

32. Joneswebb R. J., Hsiao C. Y., Hannan P. Relationships between socioeconomic-status and drinking problems among black-and-white men. Alcohol Clin Exp Res 1995; 19: $623-7$.

33. Kadushin C., Reber E., Saxe L., Livert D. The substance use system: social and neighborhood environments associated with substance use and misuse. Subst Use Misuse 1998; 33: $1681-710$

34. Wallace J. M., Forman T. A., Guthrie B. J., Bachman J. G., O'Malley P. M., Johnston L. D. The epidemiology of alcohol, tobacco and other drug use among black youth. J Stud Alcohol 1999; 60: 800-9.

35. Centers for Disease Control. Diagnostic Interview Schedule (DIS). Health Status of Vietnam Veterans. Supplement C: Medical and Psychological Procedure Manuals and Forms. Atlanta GA: Centers for Disease Control; 1989; p. 405-99.

36. Acierno R., Resnick H. S., Kilpatrick D. G., Saunders B. E., Best C. L. Risk factors for rape, physical assault, and posttraumatic stress disorder in women: examination of differential multivariate relationships. J Anxiety Disord 1999; 13: 541-6.

37. Kilpatrick D. G., Ruggiero K. J., Acierno R., Saunders B. E., Resnick H. S., Best C. L. Violence and risk of PTSD, major depression, substance abuse/dependence, and comorbidity: results from the National Survey of Adolescents. J Consult Clin Psychol 2003; 71: 692-70.

38. Resnick H. S., Kilpatrick D. G., Dansky B. S., Saunders B. E., Best C. L. Prevalence of civilian trauma and posttraumatic stress disorder in a representative national sample of women. J Consult Clin Psychol 1993; 61: 984-91.

39. Person C., Tracy M., Galea S. Risk factors for depression after a disaster. J Nerv Ment Dis 2006; 194: 659-6.

40. Nagin D. S. Group-Based Modeling of Development. Cambridge, MA: Harvard University Press; 2005.

41. Jones B. L., Nagin D., Roeder K. A SAS procedure based on mixture models for estimating developmental trajectories. Sociol Methods Res 2001; 29: 374-93.

42. Chassin L., Pitts S. C., Prost J. Binge drinking trajectories from adolescence to emerging adulthood in a high-risk sample: predictors and substance abuse outcomes. J Consult Clin Psychol 2002; 70: 67-78.

43. Gee G. C., Liang J., Bennett J. Krause N., Kobayashi E., Fukaya T. et al. Trajectories of alcohol consumption among older Japanese followed from 1987-1999. Res Aging 2007; 29: 323-47.

44. Schulenberg J., Omalley P. M., Bachman J. G., Wadsworth K. N., Johnston L. D. Getting drunk and growing up: trajectories of frequent binge drinking during the transition to young adulthood. J Stud Alcohol 1996; 57: 289-304.

45. Costanzo P. R., Malone P. S., Belsk D., Kertesz S., Pletcher M., Sloan F. A. Longitudinal differences in alcohol use in early adulthood. J Stud Alcohol Drugs 2007; 68: 727-37.

46. Wills T. A., Resko J. A., Ainette M. G., Mendoza D. Smoking onset in adolescence: a person-centered analysis with time-varying predictors. Health Psychol 2004; 23: 15867.

47. Adams R. E., Boscarino J. A., Galea S. Alcohol use, mental health status and psychological well-being 2 years after the World Trade Center attacks in New York City. Am J Drug Alcohol Abuse 2006; 32: 203-24.

48. Cooper M. L., Russell M., George W. H. Coping, expectancies, and alcohol-abuse- a test of social-learning formulations. J Abnorm Psychol 1988; 97: 218-30.

49. Stewart S. H. Alcohol abuse in individuals exposed to trauma: a critical review. Psychol Bull 1996; 120: 83112 . 
50. Thoits P. A. Stress, coping, and social support processeswhere are we-what next. J Health Soc Behav 1995; 35: 53-79.

51. Wilson N., Syme S. L., Boyce W. T., Battistich V. A., Selvin S. Adolescent alcohol, tobacco, and marijuana use: the influence of neighborhood disorder and hope. Am J Health Prom 2005; 20: 11-19.
52. Fishbein D. H., Herman-Stahl M., Eldreth D., Paschall M. J., Hyde C., Hubal R. et al. Mediators of the stress-substanceuse relationship in urban male adolescents. Prev Sci 2006; 7: 113-26.

53. Maggs J. L., Schulenberg J. E. Trajectories of alcohol use during the transition to adulthood. Alcohol Res Health 2004; 28: 195-201. 